\title{
Monitoramento do uso e ocupação de Áreas de Preservação Permanentes urbanas com o apoio de geotecnologias: $O$ caso do rio Jaguaribe em João Pessoa-PB
}

Monitoring the use and occupation of Urban Permanent Preservation Areas with the
support of geotechnologies: The case of the Jaguaribe river in João Pessoa-PB

La vigilancia del uso y ocupación de Áreas de Preservación Permanente urbanas con el apoyo de geotecnologia: El caso del río Jaguaribe en João Pessoa-PB

Joyce Priscilla de Souza Cunha Graduanda em Tecnologia em Geoprocessamento, IFPB, Brasil Joycepriscilla21@gmail.com

Roberta Cristina Félix de Lucena Graduanda em Tecnologia em Geoprocessamento, IFPB, Brasil Roberta.flucena@gmai.com

Cynthia Alves Félix de Sousa Tecnóloga em Gestão Ambiental, IFPB, Brasil Cytnhia.alvesfs@gmail.com 


\section{RESUMO}

Os rios urbanos, num contexto de crescimento urbano desordenado, têm sido os espaços naturais mais degradados, evidenciando cada vez mais a necessidade de ações voltadas para o gerenciamento urbano e ambiental sustentável. Neste cenário se encontra o município de João Pessoa, que vem apresentando em seu histórico de uso e ocupação do solo, a degradação de seus rios, como o Rio Jaguaribe. Este trabalho tem como objetivo central mostrar a utilização das geotecnologias na manipulação de dados adquiridos por sensoriamento remoto, no sentido de analisar áreas que apresentam conflitos de uso e ocupação do solo em áreas de preservação permanente, tendo como área de estudo os bairros São José e Manaíra. Para isto utilizou-se o software livre Quantum Gis para realizar a delimitação das áreas de preservação permanente, e demais análises relativas aos conflitos de uso e ocupação, acompanhado dos documentos e normas que regem o uso e ocupação do município. Os resultados indicaram a relevância das geotecnologias para os diagnósticos da situação urbana e ambiental, como ocupações irregulares, bem como sua utilização para fins de gerenciamento urbano e ambiental de áreas protegidas.

PALAVRAS-CHAVE: Gerenciamento. Rios urbanos. Uso e ocupação.

\section{ABSTRACT}

Urban rivers, in a context of disordered urban growth, have been the most degraded natural spaces, evidencing more the need for actions aimed at sustainable urban and environmental management. In this scenario is the João Pessoa city, which has been presenting in its history of land use and occupation, the degradation of its rivers, such as the Jaguaribe River. This work aims to show the use of geotechnologies in the manipulation of data acquired by remote sensing areas that present conflicts of use and occupation of the soil in areas of permanent preservation, having as study area the neighborhoods São José and Manaíra. For this purpose, the free software Quantum Gis was used to perform the delimitation of permanent preservation areas, as well as other analyzes related to conflicts of use and occupation, together with the documents and regulations governing the use and occupation of the municipality. The results indicated the relevance of geotechnologies for diagnoses of the urban and environmental situation, such as irregular occupations, as well as their use for urban and environmental management of protected areas.

KEY WORDS: Management. Urban rivers. Use and occupation.

\section{RESUMEN}

Ríos urbanos en el contexto de la expansión urbana, han sido las áreas naturales más degradados, mostrando cada vez más la necesidad de adoptar medidas para la gestión urbana y el medio ambiente sostenible. Este escenario es la ciudad de João Pessoa, que ha demostrado en su historia de uso y ocupación del suelo, la degradación de sus ríos como el Río Jaguaribe. Este trabajo tuvo como objetivo mostrar el uso de geotecnologia en el manejo de datos adquiridos por los sensores remotos, con el fin de analizar las áreas que suponen un conflicto de uso y ocupación del suelo en áreas de preservación permanente, con el área de estudio los barrios de San José y Manaíra. Para ello se utilizó el software libre de Quantum GIS para realizar la delimitación de las áreas de preservación permanente, y otros análisis relacionados con los conflictos de uso y ocupación, acompañada de los documentos y normas que rigen el uso y ocupación de la ciudad. Los resultados indican la importancia de la geo-tecnologías para el diagnóstico de la situación urbana y ambiental como la ocupación ilegal y la utilización con fines de gestión urbana y ambiental de las áreas protegidas.

PALABRAS CLAVE: Gestión. ríos urbanos. Uso y ocupación. 


\section{INTRODUÇÃO}

O crescimento urbano desordenado tem sido pauta nas principais discussões acerca dos novos paradigmas de desenvolvimento das cidades. O aumento populacional e de atividades econômicas, verificados, principalmente a partir da após a Revolução Industrial, apresentando maior proeminência após a segunda guerra mundial, têm sido apontados como as principais causas do surgimento e agravamento dos problemas urbanos diagnosticados nas últimas décadas.

As ocupações urbanas em áreas destinadas a outros fins, como as de preservação de rios e nascentes, atualmente configura expressivos problemas de planejamento urbano, devido às complexas questões socioeconômicas, políticas e ambientais envolvidas (NASCIMENTO et al., 2009).

A moradia demais ocupações em áreas de preservação permanente (APPs) expõe a população a riscos de desastres naturais. Almeida, (2012) ressalta que mesmo a legislação ambiental no que diz respeito à APP esteja em vigor, alguns fatores tem contribuído para torná-la pouco ágil, como por exemplo, a deficiência por parte do poder público em meios e materiais para apurar com rigor as agressões ao meio ambiente.

De acordo com o novo Código Florestal (Lei 12.651/12), as Áreas de Preservação Permanente (APP) são de grande importância ecológica, coberta ou não por vegetação nativa, que tem função de preservar os recursos hídricos, a paisagem, a estabilidade geológica e a biodiversidade, facilitar o fluxo gênico de fauna e flora, proteger o solo e assegurar o bemestar das populações humanas.

A necessidade de gerenciamento das áreas sensíveis/impróprias a usos urbanos em cidades de médio e grande porte é refletida nos constantes sinais de impactos ambientais e exposição da saúde e segurança dos cidadãos, principalmente em estações chuvosas, quando um cenário de risco ambiental é evidenciado nas cheias do rio.

Em um estudo realizado por Nascimento et al., (2009) foi verificado que as áreas de inaptidão e baixa aptidão para usos urbanos localizam-se na parte norte do município e em algumas áreas sujeitas às inundações periódicas devido a fatores naturais como proximidade com as calhas de drenagem, declividades baixas e nível da água raso ou aflorante. Além disto, estas são áreas de materiais arenosos retrabalhados compressíveis, o que pode acarretar instabilidade nas fundações ali instaladas. Ainda de acordo com os autores, os Bairros de Manaíra (Baixa aptidão) e São José (inaptidão) encontram-se nestas condições, sendo as áreas de maior agravamento aquelas mais próximas dos rios ou dentro de APPs.

Acredita-se que o reconhecimento dos conflitos urbanos de uso e ocupação de áreas como estas, possibilita um gerenciamento adequado, baseado nos preceitos fundamentais do planejamento urbano, orientando para a prevenção de desastres através de políticas que considerem o fator social e ambiental.

Neste sentido, as geotecnologias são ferramentas imprescindíveis para monitoramento e obtenção de informações das Áreas de Preservação Permanentes assim como inúmeros fatores ambientais, contribuindo de forma prática e eficiente, na coleta, armazenamento, manipulação, tratamento, análise e apresentação de dados geográficos. 


\section{OBJETIVO GERAL}

Realizar um diagnóstico dos conflitos de uso e ocupação do solo na APP do Rio Jaguaribe nos bairros de Manaíra e São José.

\section{METODOLOGIA}

\subsection{LOCALIZAÇÃO DA ÁREA DE ESTUDO}

O Rio Jaguaribe está localizado no município de João Pessoa, nascendo no Bairro Esplanada zona sul da cidade e percorrendo os bairros Cruz das Armas, Varjão, Jaguaribe, Castelo Branco, Manaíra, São José, Tambaú, Bessa e Miramar.

Entre os bairros de Manaíra e São José, o rio transcorre na direção do rio Paraíba e bairro do Bessa (devido a alterações ambientais antrópicas). Em todo o seu percurso, as margens do rio são acompanhadas pelas edificações e demais fundações, que geram pressão urbana nos ecossistemas associados a ele (Figura 1 ).

Figura 1. Mapa de Localização da área de estudo

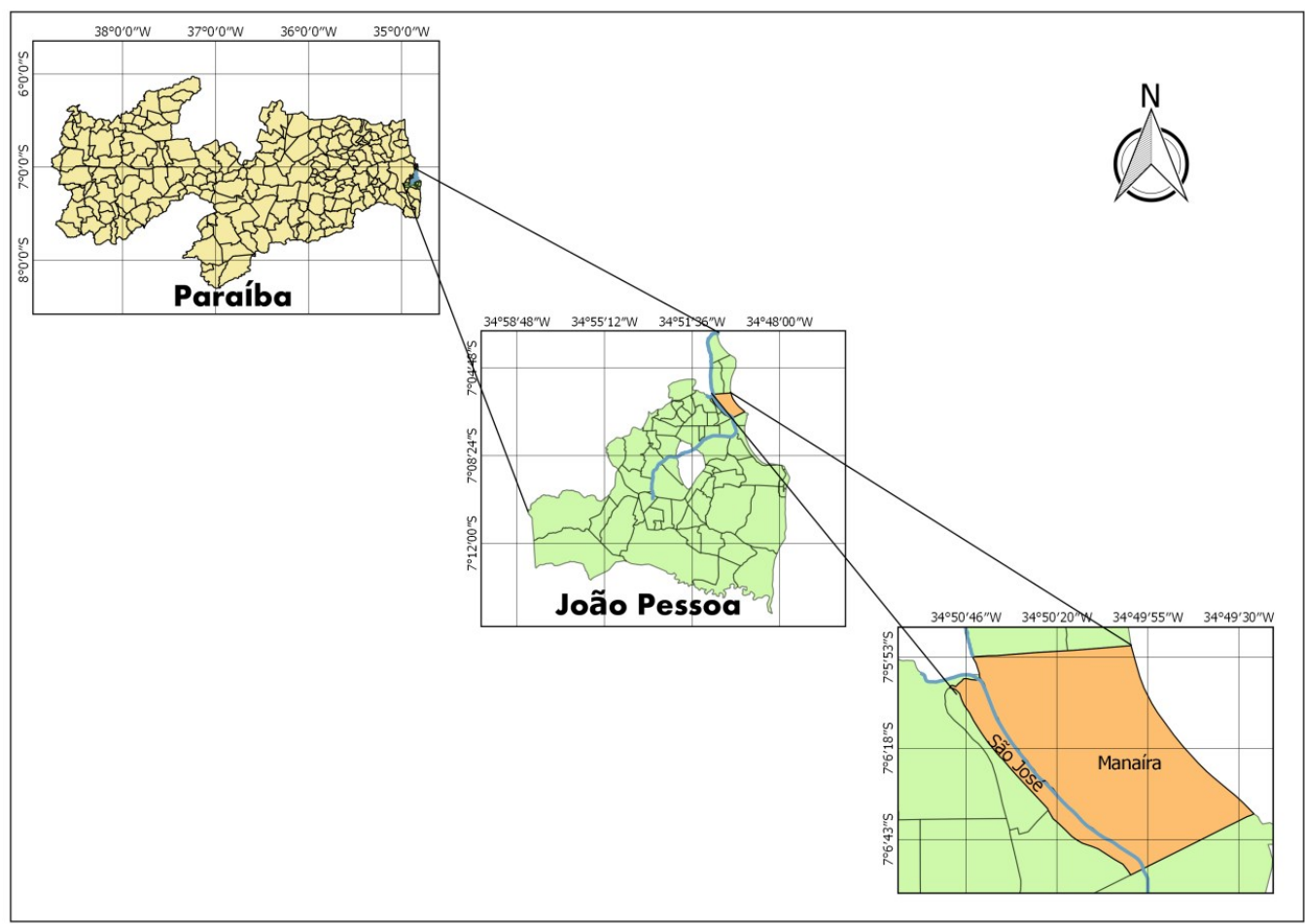

Fonte dos dados: PMJP, 2017. Elaboração própria.

O Bairro São José surgiu como um assentamento espontâneo e informal desordenado de migrantes de baixo poder aquisitivo que ocuparam sem licença toda a margem do Rio Jaguaribe, considerado Área de Preservação Permanente (APP). Isto acarretou graves prejuízos ambientais e sociais. 


\subsection{AQUISIÇÃO E ANÁLISE DOS DADOS}

Como suporte teórico, esta pesquisa baseou-se nos levantamentos bibliográficos como de artigos científicos e dissertações; como base técnica, tiveram-se como base os documentos como o Código de urbanismo e o Código Ambiental municipal de João Pessoa e o código florestal em vigor.

Como suporte ao trabalho prático utilizou-se o software livre de sistemas de informações geográficas (SIG) Quantum GIS versão 2.14.4, arquivo no formato shapefile de bairros, lotes e rio, adquiridos no site da Prefeitura municipal de João Pessoa (Jampa em Mapas) e da Paraíba adquirido no site do IBGE.

Para a realização deste trabalho seguiu-se as seguintes etapas metodológicas descritas na figura abaixo:

Figura 2: Etapas metodológicas
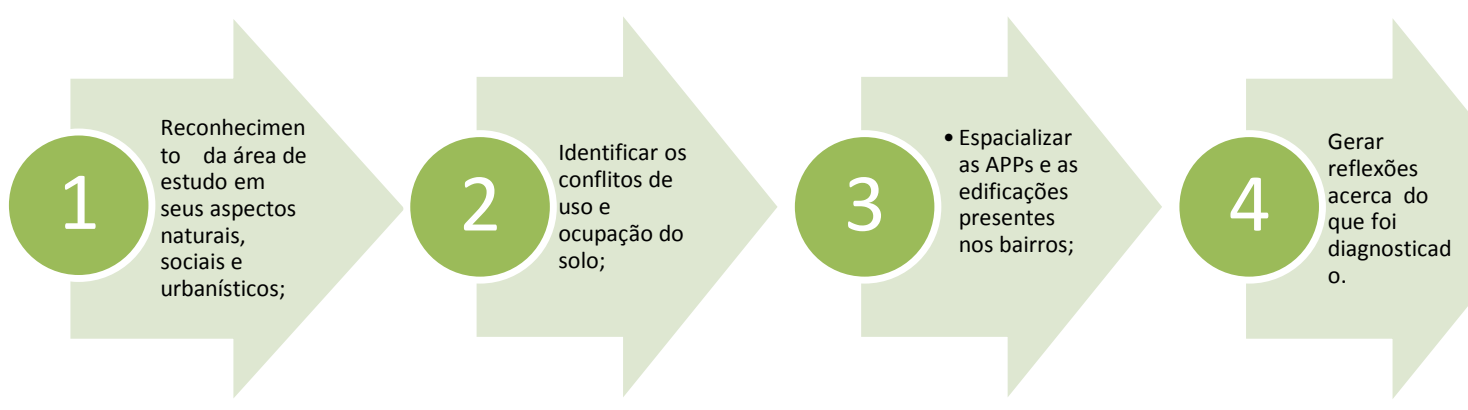

\section{RESULTADOS}

Obteve-se a largura do rio através da análise de imagens de satélites cedidas através do Google Earth datadas de 09/07/2016, com a ferramenta Régua (Figura 3). Assim, obteve-se que a largura do rio foi de até $10 \mathrm{~m}$ em todo o trecho estudado. De acordo com o código florestal Lei 12.651 de 25 de maio de 2012, as larguras das APPs devem respeitar as seguintes determinações:

as faixas marginais de qualquer curso d'água natural perene e intermitente, excluídos os efêmeros, desde a borda da calha do leito regular, em largura mínima de: a) $\mathbf{3 0}$ (trinta) metros, para os cursos d'água de menos de 10 (dez) metros de largura; b) 50 (cinquenta) metros, para os cursos d'água que tenham de 10 (dez) a 50 (cinquenta) metros de largura; c) 100 (cem) metros, para os cursos d'água que tenham de 50 (cinquenta) a 200 (duzentos) metros de largura.

Assim, no software QGIS, com a ferramenta buffer foi possível estabelecer a delimitação das áreas de preservação permanente. Como o rio possui uma largura de aproximadamente $9 \mathrm{~m}$, foi gerado um buffer de 30 metros sobre a rede de drenagem hidrográfica (Figura 3). 


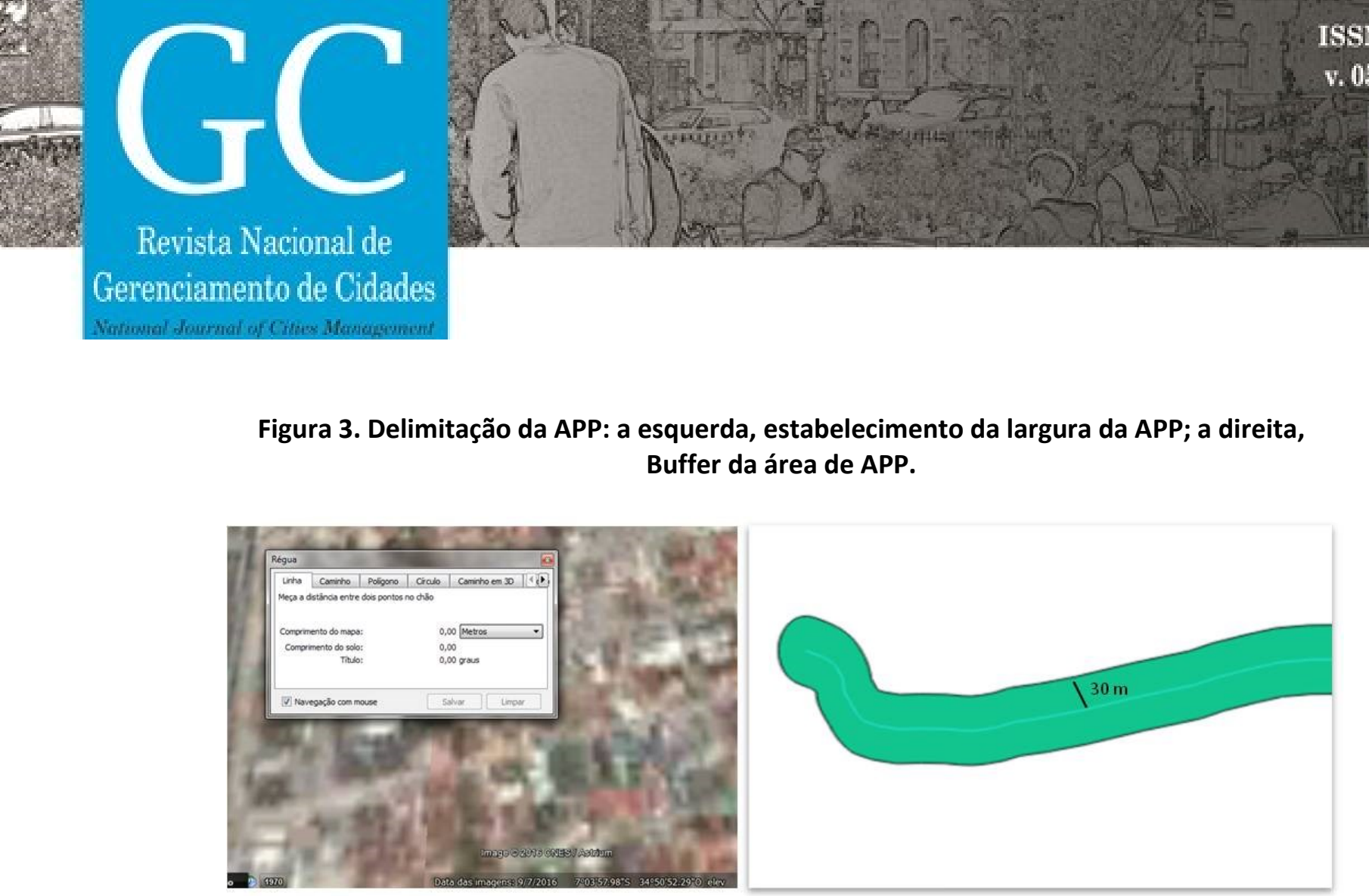

Após a determinação da área de APP foram verificadas edificações inseridas em conflito de uso e ocupação do solo, considerando inclusive o disposto na mesma lei:

$\S 5^{\circ}$ É admitido, para a pequena propriedade ou posse rural familiar, de que trata o inciso $\mathrm{V}$ do art. $3^{\circ}$ desta Lei, o plantio de culturas temporárias e sazonais de vazante de ciclo curto na faixa de terra que fica exposta no período de vazante dos rios ou lagos, desde que não implique supressão de novas áreas de vegetação nativa, seja conservada a qualidade da água e do solo e seja protegida a fauna silvestre.

Apesar da problemática que envolve as ocupações próximas aos rios urbanos, como riscos ambientais, a comunidade está presente nesta localidade desde 1960, e até hoje conserva estas carências urbanas e ambientais (SANTOS, 2007) (Figura 4).

Figura 4: Moradias construídas ao longo das margens do rio Jaguaribe, Bairro São José.
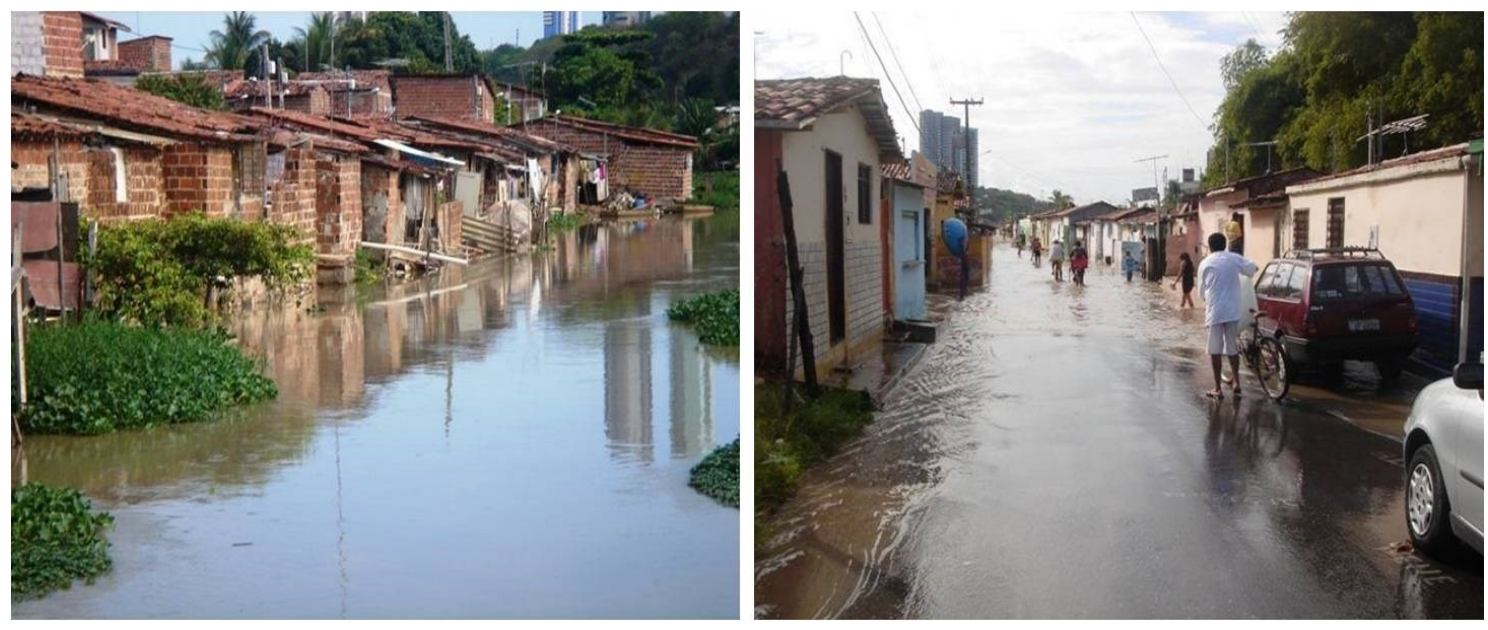


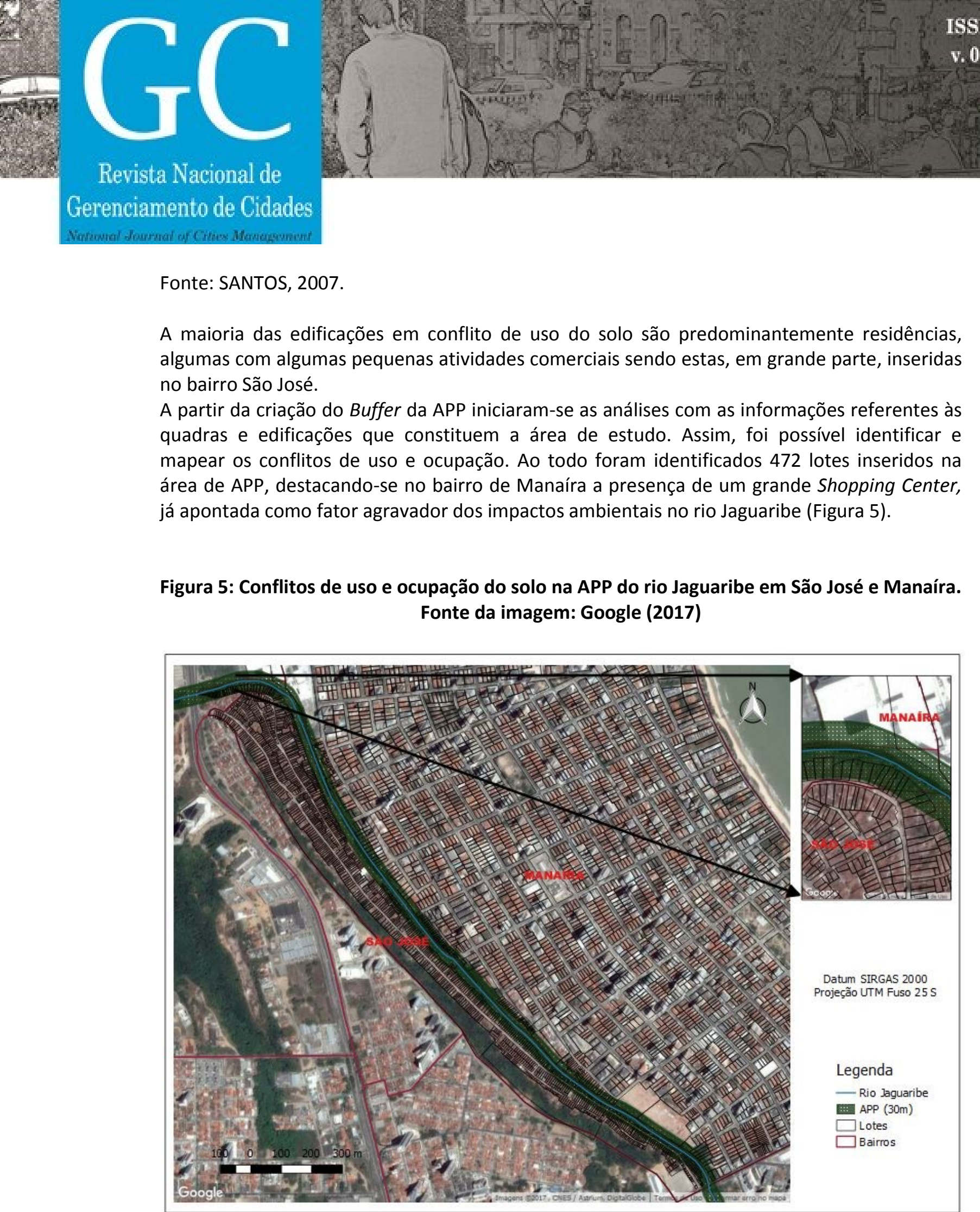

Fonte dos dados: PMJP, 2017; GOOGLE, 2017. Elaboração própria.

De acordo com Nascimento et al., (2009), os bairros de Manaíra e São José não estão em um espaço ideal para usos urbanos, dadas as condições naturais da localidade (principalmente referindo-se a geomorfologia, hidrologia e pedologia). Este fator, aliado a falta de planejamento urbano, destruição da mata ciliar acarreta em situações de inundações e exposição a riscos (Figura 6). 


\section{REFERÊNCIAS}

BRASIL. CONSELHO NACIONAL DO MEIO AMBIENTE (CONAMA). 2002. Resolução Conama no 303. Disponível em:< www.mma.conama.gov.br/conama> Acesso em 27 de agosto 2016.

BRASIL, Lei 12.651, de 25 de maio de 2012. Código Florestal Brasileiro. Disponível em: <brasil.gov.br> em Acesso em 27 de agosto 2016.

INSTITUTO BRASILEIRO DE GEOGRAFIA E ESTATISTICA - IBGE, 2010. Cidades brasileiras. Disponível em: $<w w w . c i d a d e s . i b g e . g o v . b r>$ Acesso em 23 de agosto 2016.

LIMA, Marco Antônio Suassuna. Segregação sócio-espacial e desenho urbano em assentamento espontâneo: o caso do bairro São José em João Pessoa PB. Revista Monólito Arquitetura como Cultura. Vol. 072.06 Maio, 2006: ISSN1809-6298. Disponível em: <http://www.vitruvius.com.br/revista/reas/arquitextos/06.072/356>. Acesso em: 25 de agosto 2016.

MEDEIROS, Maria Cristina Silva; Silva Junior, Josué Barreto. Estudo de caso da expansão do shopping Manaíra e comunidade São José sobre o rio Jaguaribe Em João Pessoa-PB. Disponível em: < http://www.epublicacoes.uerj.br/index.php/polemica/rt/printerFriendly/22903/16386 >. Acesso: 26 de agosto 2016.

NASCIMENTO, Vânia Maria Lima Carneiro; LIMA, Eduardo Rodrigues Viana de; SANTOS, Celso Augusto Guimarães. Utilização de sistema de informações geográficas na avaliação de áreas para ocupação urbana em João Pessoa/PB. XIV simpósio brasileiro de sensoriamento remoto. p.4093-4100. Natal. 2009.

SANTOS, Jocélio Araújo dos. Análise dos riscos ambientais relacionados às enchentes e deslizamentos na favela São José, João Pessoa - PB. 2007. 112 f. Dissertação (Mestrado) - Curso de Programa de Pós-graduação em Geografia, Ufpb, João Pessoa, 2007.

SILVA, Marcio Sousa da; LEMOS, Sílvio Santos de e MORAES, Allana Bezerra de. Uso de geotecnologias para delimitação de Áreas de Preservação Permanente e análise das áreas de conflito de uso e ocupação do solo na zona urbana do município de Mãe do Rio - PA. Disponível em: < http://anpur.org.br/app-urbana2014/anais/ARQUIVOS/GT3-72-33-20140518141544.pdf >. Acesso: 27 de agosto 2016.

PMJP. PREFEITURA MUNICIPAL DE JOÃO PESSOA. Departamento de Geoprocessamento. Disponível em: < http://geo.joaopessoa.pb.gov.br/digeoc/htmls/>. Acesso em: 26 de fev. de 2016.

RESENDE, André. Rio separa bairro mais pobre de João Pessoa de um dos mais ricos. G1. João Pessoa, p. 1-1. 06 ago. 2015. Disponível em: <http://g1.globo.com/pb/paraiba/noticia/2015/08/rio-separa-bairro-mais-pobre-de-joaopessoa-de-um-dos-mais-ricos.html>. Acesso em: $10 \mathrm{dez} .2016$. 